\section{Incidence of gastro-intestinal parasites in wild ruminants around Jabalpur, India}

\section{Abhishek Gupta ${ }^{1}$, A.K. Dixit ${ }^{2}$, Pooja Dixit ${ }^{3}$, Chetna Mahajan ${ }^{4}$ \& A.B. Shrivastava ${ }^{5}$}

\begin{abstract}
${ }^{1,2}$ Department of Parasitology, ${ }^{3}$ Department of Veterinary Medicine, ${ }^{5}$ Department of Wildlife Health and Management, College of Veterinary Science \& Animal Husbandry, MPPCVV, Jabalpur, Madhya Pradesh 482001, India

${ }^{4}$ Department of Biochemistry, College of Veterinary \& Animal Science, MPUAT, Udaipur, Rajasthan 313601, India Email: ${ }^{2}$ alokdixit7@yahoo.com (corresponding author)
\end{abstract}

Parasitic infections can cause disease and death in wild animals and can become a source of infection for domestic animals. Epidemiological studies are important to know about the status and transmission of diseases.

Parasitic diseases are best controlled by preventing the contact and parasite transmission between wild and domestic animals and by manipulating the factors involved in the disease transmission.

Establishing a data base to predict the disease by performing epidemiological studies round the year is of utmost importance and needs attention (Shrivastava 2003).

Methods: Fifty faecal samples of wild animals including 15 samples of Chital Axis axis, 15 of Neelgai Boselaphus tragocamelus, 10 of Gaur Bos gaurus and 10 of Sambar Rusa unicolor were collected from the peripheral forests around Jabalpur. Faecal samples

Date of publication (online): 26 November 2011

Date of publication (print): 26 November 2011

ISSN 0974-7907 (online) | 0974-7893 (print)

Editor: Ulrike Streicher

\section{Manuscript details:}

Ms \# 02431

Received 29 March 2010

Final received 13 October 2011

Finally accepted 15 October 2011

Citation: Gupta, A., A.K. Dixit, P. Dixit, C. Mahajan \& A.B. Shrivastava (2011). Incidence of gastro-intestinal parasites in wild ruminants around Jabalpur, India. Journal of Threatened Taxa 3(11): 2226-2228.

Copyright: (C) Abhishek Gupta, A.K. Dixit, Pooja Dixit, Chetna Mahajan \& A.B. Shrivastava 2011. Creative Commons Attribution 3.0 Unported License. JoTT allows unrestricted use of this article in any medium for non-profit purposes, reproduction and distribution by providing adequate credit to the authors and the source of publication.

OPEN ACCESS | FREE DOWNLOAD were subjected to coprological examination as per the method of Sloss et al. (1994) with a few

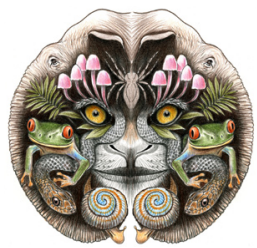
modifications. Briefly, $2 \mathrm{~g}$ of strained faecal sample was mixed with tap water in a $15 \mathrm{ml}$ centrifuge tube and centrifuged for $1-2 \mathrm{~min}$ at 1500-2000 rpm. The supernatant was removed and similarly two washings were given until the supernatant remained clear. After the last washing, the faecal decant at the bottom of the tube was mixed with sheather's sugar solution and was filled up to the brim and was covered with a clean coverslip. Then it was centrifuged at 1500-2000 rpm for two minutes. The coverslip was removed from the top, placed on clean glass slide and examined for helminths and their eggs. The supernatant fluid which remained in the tube after removing coverslip was drained off leaving the bottom sediment. The sediment was resuspended in few drops of water. One or two drops of sediment was taken on microscopic slide and examined microscopically under low magnification for trematode eggs. Identification of eggs was made by observing their characters (Soulsby 1986).

Results: Coprological examination of different wild herbivores found the highest rate of parasitic infection in Sambar (90.0\%) followed by Neelgai $(86.67 \%)$ and Gaur and Chital (80.0\%) (Table 1).

Ninety-four percent of the parasitic infections were mixed infections comprising multiple different parasite species whereas only $6.0 \%$ consisted of only one parasite species.

In Sambar, the parasitic profile was dominated by Coccidia infection (60.0\%) followed by Strongylides (50.0\%). Amphistoma (30.0\%) and Strongyloides $(30.0 \%)$ showed equal prevalence followed by Trichuris (20.0\%) and Fasciola (10.0\%). In Chital, the prevalence of Strongylides (60.0\%) was the highest followed by Trichuris (53.3\%) and Fasciola (6.7\%)

Table 1. Overall prevalence of parasitic infection in wild herbivores

\begin{tabular}{|c|c|c|c|c|c|}
\hline & Animal & $\begin{array}{c}\text { Total } \\
\text { number }\end{array}$ & Infected & $\begin{array}{c}\text { Non- } \\
\text { infected }\end{array}$ & $\%$ \\
\hline 1 & Chital & 15 & 12 & 3 & 80.0 \\
\hline 2 & Neelgai & 15 & 13 & 2 & 86.67 \\
\hline 3 & Gaur & 10 & 8 & 2 & 80.0 \\
\hline 4 & Sambar & 10 & 9 & 1 & 90.0 \\
\hline
\end{tabular}




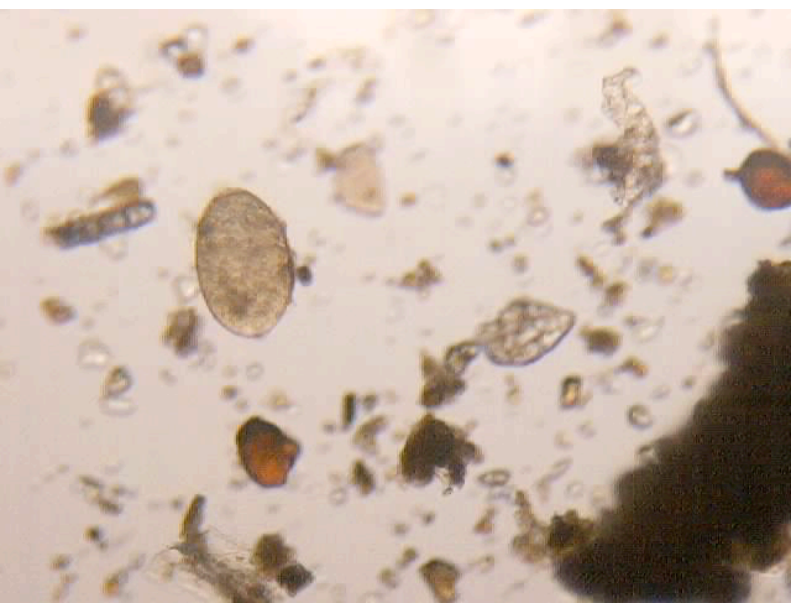

Image 1. Egg of Fasciola gigantica in faecal sample of Chital

(Image 1).

Neelgai showed equal prevalence of Strongylides (66.7\%) and Trichuris (66.7\%) followed by Coccidia (60.0\%). Amphistoma infection was found in 46.7\%, where as Fasciola was present in only 6.7\%. Moniezia occurred at a rate of $13.0 \%$. In Gaur finally Trichuris $(70.0 \%)$ was the dominant parasite followed by Strongylides (60.0\%) and Coccidia (60.0\%). Amphistoma (30.0\%) and Strongyloides (30.0\%) showed a similar prevalence and Fasciola (Fasciola gigantica) was found in $10 \%$ of the Gaur samples (Fig. 1).

Discussion: Most of the samples were collected around villages close to the forest areas. The prevalence of Trichuris, Strongylides and Coccidia was high in most of the wild animals in our study. This might be due to contamination of pastures by the grazing of domestic animals.

Of special interest was the infection with Fasciola found in all species of wild herbivores. One reason for this could be that domestic animals are competing with the wild animals for grazing areas in the forests and force wild animals to graze in swampy areas thus exposing them to vegetation infected with metacercaria of Fasciola.

Fasciola gigantica among the wild cervids and other herbivores of India has been reported from Spotted Deer Axis axis and Black Buck Antelope cervicapra by Rao \& Acharjyo (1969, 1972), Swamp Deer Rucervus duvauceli duvauceli by Verma et al. (1994) and Indian Rhinoceros Rhinoceros unicornis by Bhattacharjee $\&$ Haldar (1971). In addition, eggs of Fasciola were

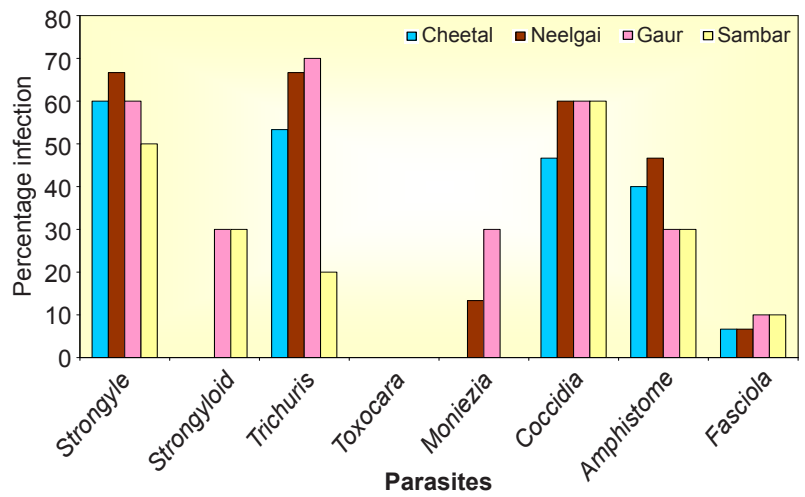

Figure 1. Parasitewise infection in wild herbivores

detected in faeces of Chitals and Sambars of Corbett National Park, Ramnagar and Wildlife National Park at Dudwa in Uttar Pradesh (Gaur et al. 1979; Arora et al. 1985). Incidence of Fasciola was also reported from Chital, Sambar and Neelgai at Pench Tiger Reserve, Madhya Pradesh (Shrivastava et al. 2005). Our study reports the occurrence of $F$. gigantica from Gaur and there seems to be no previous report on $F$. gigantica in Gaur from India.

Our study provides a first overview on parasites in wild ruminants in the vicinity of villages, but to evaluate parasite transmission rates much more studies are required on livestock in the area and on wild herbivores in areas where they do not compete with livestock.

\section{REFERENCES}

Arora, B.M., P.N. Bhat \& K. Ramaswamy (1985). Survey of gastrointestinal parasitic infection of free and wild animals. FAO field document No. 5. Proceedings of the Workshop on Wildlife Health for Vets, Dehradun, U.P., India.

Bhattacharjee, M.L. \& B.R. Haldar (1971). The occurrence of Fasciola gigantica in the liver of an Indain Rhinoceros (Rhinoceros unicornis). British Veterinary Journal 127: 7-8.

Gaur, S.N.S., M.S. Sethi, H.C. Tewari \& O. Prakash (1979). A note on prevalence of helminth parasites in wild and zoo animals in Uttar Pradesh. Indian Journal of Animal Science 46: 159-161.

Rao, A.T. \& L.N. Acharjyo (1969). Histopathological changes in the liver of a Spotted Deer (Axis axis) infected with Fasciola gigantica. Indian Veterinary Journal 46: 36-38.

Rao, A.T. \& L.N. Acharjyo (1972). Further observations on fasciolosis among wild ungulates at Nandan Kanan Zoo. Indian Veterinary Journal 49: 133-135.

Shrivastava, A.B. (2003). History of wildlife diseases with 
particular reference to India, pp. 146-147. In: National Symposium on Basic Pathology and Animal Disease-A Need for Fresh Approach in Indian Scenario and XX Annual Conference of Indian Association of Veterinary Pathologist, Jabalpur.

Shrivastava, A.B., R.K. Sharma \& D. Nagar (2005). Observation and Results. Final Report. Surveillance of infectious and parasitic diseases of native wild animals of Pench Tiger Reserve.

Sloss, M.W., R.L. Kemp \& A.M. Zajac (1994). Veterinary
Clinical Parasitology. International Book Distributing Co., Lucknow, 5-11pp.

Soulsby, E.J.L. (1986). Helminths, Arthropods and Protozoa of Domesticated Animals. 7th edn. London, Bailliere and Tindall, 767-771pp.

Verma, T.K., A. Prasad, B.M. Arora \& H.C. Malviya (1994). Occurrence of Fasciola gigantica from the bile duct of a Swamp Deer (Cervus duvauceli duvauceli). Indian Veterinary Journal 8: 95-96. 